\title{
A NOTE ON THE VASCULARIZATION OF THE OPTIC NERVE
}

\author{
BY \\ J. FRANÇOIS AND A. NEETENS \\ From the Ophthalmic Clinic, University of Ghent, Belgium
}

It has been brought to our notice by Dr. S. Singh Hayreh-to whom we are very grateful - that an error has appeared in the illustrations to our paper which was published in this Journal last January (Brit. J. Ophthal., 1963, 47, 21).

Fig. 7, p. 27, which purports to be a transverse section of the anterior part of the human optic nerve, in which the vascular circulation is outlined by a Thorotrast injection through the ophthalmic artery after the ligation of the central retinal artery at its origin, is in fact a mirror-image of Fig. 6 from a previous paper (Brit. J. Ophthal., 1955, 39, 220), which illustrated the posterior part of the nerve.

The mistake occurred inadvertently in choosing from the multitude of very similar slides in our laboratory; the correct illustration of the anterior part of the nerve, to which the text in our recent paper applies, is reproduced below.

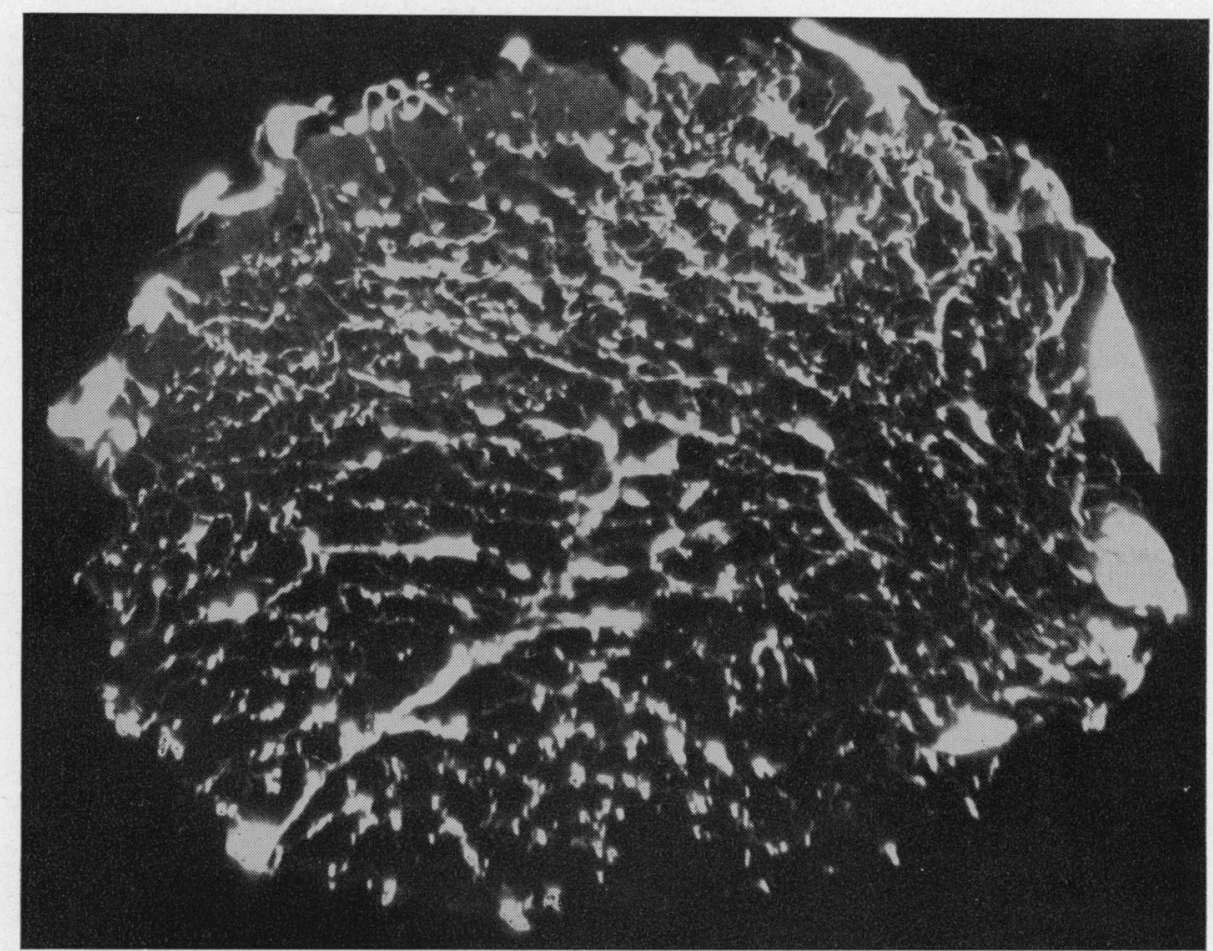

FIGURE.-Transverse section of the anterior part of the human optic nerve. Thorotrast injection through the ophthalmic artery, after ligation of the central retinal artery at its origin ( $\times 14)$. 